\title{
La comprensión de la alteridad sorda desde una perspectiva sociocultural
}

\author{
Understanding of deaf otherness from a sociocultural perspective
}

\begin{abstract}
Resumen
El presente trabajo busca dar cuenta de cómo se construyen las relaciones entre las personas sordas y oyentes que conforman la comunidad sorda de la Asociación de Personas Sordas de Ourense (APSOU). A través de la inmersión en sus dinámicas de interacción, es posible ofrecer una descripción etnográfica sobre las formas de ser del -otro- sordo como minoría lingüística y cultural. Los criterios de exclusión en su comunidad se articulan en torno a la construcción de límites de acceso al - otro- oyente. Por su parte, - las fórmulas de inclusión - necesitan de la consolidación identitaria como persona sorda, así como de la incorporación de la propia lengua - de signos - y cultura. La comprensión de la dualidad identidad/otredad a partir de las capacidades culturales desarrolladas, permite orientar la intervención social con el colectivo de personas sordas desde una perspectiva sociocultural en oposición a una médica-rehabilitadora basada en las nociones de minusvalía o discapacidad.
\end{abstract}

\section{Palabras clave}

Comunidad sorda, lengua de signos, cultura, identidad, otredad, minoría lingüística y cultural, perspectiva sociocultural, inclusión-exclusión.

\begin{abstract}
The following paper seeks to determine how the relationships between deaf people and hearing people who make up the deaf community of the deaf people's Association of Ourense are built. Through the immersion in their dynamics of interaction it is possible to offer an ethnographic description on the ways of being of the -otherdeaf as linguistic and cultural minority. The exclusion approaches of their community are articulated around the construction of the access to the -other- hearing people and the forms of inclusion, they need an identity consolidation like a deaf person and the in-corporation of the own language-sign language- and culture.The understanding of duality identity/otherness, based on development cultural capacities, allows to guide social intervention with the collective of deaf people from a sociocultural perspective in opposition to a medical-rehabilitative based on notions of disability or handicap.
\end{abstract}

\section{Keywords}

Deaf community, sign language, culture, identity, otherness, cultural and linguistic minority, socio-cultural perspective, inclusion-exclusion.

\section{Leticia González Mosquera <leticiagonzmos@gmail.com>}

Consorcio Galego de Servizos de Igualdade e Benestar. España

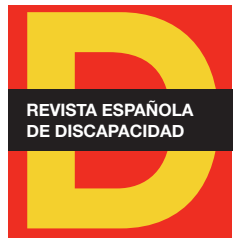

Para citar:

González, L. (2020). "La comprensión de la alteridad sorda desde una perspectiva sociocultural". Revista Española de Discapacidad, 8(I), pp. 159-180.

Doi: <https://doi.org/10.5569/23405104.08.01.09>

Fecha de recepción: 13-08-2019 Fecha de aceptación: 25-05-2020 


\section{Introducción}

Las personas sordas constituyen una minoría lingüística y cultural que convive con una mayoría oyente en un contexto de diglosia y de desigualdad en el acceso a la información y los recursos. Su identidad, se construye en una fluctuación constante entre dos mundos, dos lenguas y formas de ser muy diferentes que les dota de unas características específicas.

El interés académico por sus peculiaridades socio antropológicas y por la presencia de características culturales propias en las comunidades de personas sordas en todo el mundo es relativamente reciente. En su mayor parte, los estudios sobre el tema han trabajado bajo la consideración de la sordera como una patología que era necesario curar: "el modelo tradicional, oral y con base médica, tiene un objetivo primordial: rehabilitar al deficiente auditivo". (Chavarría,1994). Ejemplos de este tratamiento patológico son, según sus testimonios: duras sesiones de rehabilitación encaminadas a conseguir la adquisición de la lengua oral con la exclusión de su lengua natural - la lengua de signos - en el proceso, o la prescripción de prótesis auditivas e implantes cocleares de forma sistemática sin atender a las características y necesidades particulares de individuos y familias. Así, desde una perspectiva de asimilación, se pretendía "integrar" a las personas sordas en la sociedad oyente mayoritaria sin tener en cuenta sus especificidades.

Mi interés en el estudio de las personas sordas como comunidad diferenciada, con una cultura, identidad y lengua propias, surge de la inmersión en ella como miembro. El primer contacto con la comunidad sorda tiene lugar en el año 2007 cuando resulto seleccionada como trabajadora social para comenzar a trabajar en una asociación provincial. A partir del desempeño de este rol, pronto se hace patente que una correcta intervención profesional necesita de un conocimiento profundo de la comunidad y su contexto. Para conseguir cuanto antes una independencia comunicativa, me inscribo en los cursos de Lengua de Signos Española, a partir de ahora (LSE), que se imparten en la misma entidad y junto con el empeño de los propios nativos en que fuera capaz de entenderme con ellos y ellas sin mediación de ningún intérprete de lengua de signos, consigo cada vez una mayor competencia lingüística. Tiempo después, me inscribo como socia de la asociación lo que me permite participar activamente en multitud de eventos, conferencias, encuentros y actividades. A partir de la incorporación a la comunidad, solicité el permiso oportuno para realizar un trabajo de campo aprovechando mi formación como antropóloga social y cultural. El presente texto se nutre de los datos de campo recogidos con parte de la comunidad de personas sordas de la provincia de Ourense que se reunía en la asociación de personas sordas de la misma durante los años 2014-2015. Los datos se han recogido a partir de la observación como participante fundamentalmente en dicho contexto de interacción, de entrevistas en profundidad a personas sordas, así como a través de cuestionarios de respuesta abierta a miembros de la comunidad realizándose, en el caso de las primeras, en LSE, sin personas intermediarias, esto es, sin la presencia de la figura del Intérprete de Lengua de Signos Española, a partir de ahora ILSE'.

El objetivo principal de este artículo es lograr un acercamiento a lo que es una persona sorda a través de sus propios testimonios, a cómo construyen la percepción sobre sí mismos y sobre "los otros" oyentes en las dinámicas de interacción dentro de su comunidad. Al interpretar los significados de las realidades de

1. Intérprete de lengua de signos: profesional que interpreta y traduce la información de la lengua de signos a la lengua oral y escrita y viceversa con el fin de asegurar la comunicación entre las personas sordas, con discapacidad auditiva y sordociegas, que sean usuarias de esta lengua, y su entorno social. (Ley 27/2002 de 23 de octubre:43255). 
las personas sordas, busco ofrecer un mayor conocimiento sobre el colectivo, aportando información útil para una intervención más exitosa desde una perspectiva sociocultural dando visibilidad a las principales carencias que las personas sordas perciben en el modelo actual de incorporación social.

En un contexto de individuos en relación, pertenecientes al mundo sordo y al oyente, y prestando atención a cómo se construye y deconstruye la mismidad en contraste con la otredad, se busca encontrar al otro para definir al mismo. Ramírez (2011), ofrece la siguiente definición alteridad:

Alteridad, otredad ('Otherness'), significa la clasificación socialmente construida y subjetivamente incorporada de personas y gentes como diversas por algún criterio identificativo/adscriptivo. Si la identidad remitía a semejanza, parecido, identificación con un modelo y/o colectividad, a través de un proceso de selección de algo a lo que asemejarse, en la alteridad, la alterización, se produce necesariamente el movimiento inverso: personas y grupos que uno no hace sus iguales. (pp.188).

Para abordar los procesos implicados en la objetivación de la identidad y su construcción frente a la alteridad se ha explorado la etnogénesis y posterior consolidación identitaria de las personas sordas. Desde un principio se observa la trascendencia con respecto a una identidad configurada únicamente en torno a elementos culturalmente diferenciados:

La identidad cultural se mediría por la adherencia que tiene cada individuo a las creencias y costumbres de la comunidad (...). Pero es más que eso. Es el sentido de proximidad a los otros, eliminar barreras y no necesitar negociar las normas de interacción. Es un sentimiento de compartir experiencia del mundo. Eso es la identidad de ser Sordo. Es fácilmente reconocido no sólo por los participantes sino también por aquellos que observan (Kyle, 1990:183).

La comprensión de la importancia de la comunidad sorda - distinguen terminológicamente a la comunidad, en la que incluyen a las personas oyentes pertenecientes a la misma, de colectivo, en el que sólo quedarían representadas las personas sordas - es esencial para acceder al análisis de identidades y alteridades del grupo étnico. Por un lado, se pretende la definición de los límites de inclusión en el grupo -a través de la investigación de los criterios de exclusión y alterización-, por el otro, la posibilidad de adscripción a la comunidad sorda, -criterios de inclusión, identificación- pasa por una exploración de la descripción de sus identidades y del papel determinante de la lengua de signos y de la cultura sorda en estos procesos.

Su definición emic de identidad gira en torno a la percepción visual del mundo, la importancia de su lengua, su historia y producciones culturales. Pero, ¿Cómo configura la experiencia perceptiva visual la identidad individual y colectiva? ¿Cómo se traducen esos valores y costumbres que se atribuyen como propios en prácticas concretas o pautas de conductas específicas del colectivo? Esta percepción visual del mundo, ¿genera una identidad individual común anterior al fenómeno colectivo o se produce y reproduce a través de él? 
2. Metodología y diseño de investigación: procedimiento de obtención y categorización de datos

Se ha llevado a cabo la realización de un trabajo de campo en la Asociación de Personas Sordas de Ourense (APSOU) durante los años 2014-2015, a través de la práctica etnográfica empleando la observación participante y toma de notas en situaciones de intercambio e interacción de rutinas con personas sordas. El trabajo de campo "es una situación metodológica y también en sí mismo un proceso, una secuencia de acciones, de comportamientos y de acontecimientos, no todo controlados por el investigador, cuyos objetivos pueden ordenarse en un eje de inmediatez y lejanía". (Velasco y Diaz de Rada, 1997:18).

Se ha empleado una metodología cualitativa naturalista, siguiendo a Valles (2000:148): "la observación cualitativa es fundamentalmente naturalista en esencia; ocurre en el contexto natural de ocurrencia, entre los actores que estuviesen naturalmente participando en la interacción y sigue el curso natural de la vida cotidiana". Esta inmersión, junto con la técnica de la observación participante, me permitió adoptar una dinámica de cercanía y extrañamiento. Bajo la lógica de la doble condición de miembro y extraña pude ir captando las pautas, valores y normas insertas en mis observaciones, en nuestras conversaciones casuales y en las dinámicas de vida del grupo. El acceso a la objetividad fue posible entendiendo y percibiendo sus realidades como intersubjetivas y manteniendo un carácter reflexivo que me permitiera separar mis roles como profesional, miembro de la comunidad e investigadora.

La adquisición de un buen nivel de competencia lingüística, tras el apoyo formativo, la inmersión como miembro activo en la comunidad, y 6 años de intervención social profesional diaria con personas sordas como trabajadora social, me posibilitó el acceso a la recogida de datos a través de entrevistas en profundidad con personas sordas de la comunidad. El diseño de estas se realizó por categorías de análisis previamente definidas, repensando previamente las preguntas principales que podrían ir asociadas a las mismas tras un ejercicio de reflexividad con el objetivo de "construir paso a paso y minuciosamente la experiencia del otro" (Robles, 2011). Se inició la observación participante en el año 2014, si bien se lleva a cabo la realización de las entrevistas en el 2015 y el análisis de los datos durante el 2018. Se ha utilizado un enfoque holístico, manteniendo un especial interés por las descripciones emic de la comunidad sorda y un posterior análisis cualitativo de los fenómenos observados.

El perfil de las personas entrevistadas responde a la búsqueda de diferentes posiciones dentro de la comunidad. Así, se han realizado 4entrevistas en profundidad semiestructuradas a personas sordas y tres cuestionarios de respuesta abierta a personas oyentes. Las entrevistas realizadas a las personas sordas fueron grabadas en vídeo en LSE. Al conocer la lengua nativa y no necesitar el uso de ILSE se realizaron las preguntas en su propia lengua. Se llevó a cabo una traducción mediante el proceso de traducción de la LSE (lengua viso-gestual) a lengua castellana (canal audio-vocal)y posteriormente una transcripción a lengua castellana escrita (soporte escrito). Esto implica el trabajo simultáneo de visualización-traducción-interpretación del contenido grabado en vídeo a la lengua castellana y su transcripción en lengua castellana escrita.

Las personas sordas entrevistadas fueron las siguientes:

- Una mujer líder en la comunidad: me pareció oportuna su selección debido a su estatus en la comunidad, la de cargo político en el movimiento asociativo 
- Un hombre profesor de LSE: las profundas implicaciones de la lengua de signos en todas las categorías teóricas de la investigación me llevaron a contar con un especialista en la materia.

- Un hombre hipoacúsico integrado en la comunidad sorda: la selección de este perfil la consideré importante para la descripción de los fenómenos identitarios, la delimitación étnica y los procesos de acogida e inclusión en la comunidad.

- Un hombre sordo trabajador social: la opinión de un compañero nativo me pareció muy significativa para definir una perspectiva sociocultural para la intervención social.

En cuanto a las personas oyentes, solicitaron la realización de cuestionarios para poder reflexionar sobre mis categorías de investigación sin la presión de ofrecer la respuesta inmediata que exige la grabación de una entrevista en profundidad. El diseño del cuestionario se realizó bajo el mismo criterio y procedimiento metodológico utilizado para las entrevistas en profundidad realizadas a personas sordas, si bien, debido a la naturaleza de la recogida de datos, las preguntas asociadas a las categorías eran más específicas pero lo suficientemente flexibles para obtener una respuesta amplia.

En cuanto a las personas oyentes participaron:

- Una ILSE: constituye una figura clave en la comunidad, forma parte de las rutinas de las personas sordas y practica diariamente una interpretación cultural.

- Dos ${ }^{2}$ CODA: dos hijas de padres sordos. "La palabra CODA significa Children Of Deaf Adults, o sea, hijos de padres sordos, es un término utilizado por la Organización Internacional CODA". (De Melo, 2015:88). Su punto de vista con respecto a las formas de ser, identidades y comportamientos de las personas sordas es muy amplio y valioso con infinidad de contenidos y experiencias.

Posteriormente se llevó a cabo la categorización, codificación y clasificación de los datos obtenidos, a través de las técnicas de observación participante y entrevista, en unidades analíticas. Finalmente, empleando una metodología reflexiva e interpretativa para acceder a las distintas unidades de significado, se procedió al análisis comparativo de resultados obtenidos a través de las voces de las personas sordas y oyentes de la comunidad junto con las notas recogidas durante el trabajo de campo.

Se han utilizado las siguientes categorías de análisis:

- Debilidades detectadas para un modelo sociocultural inclusivo y sin barreras.

- Comunidad sorda: criterios de pertenencia y límites de acceso.

- Choques culturales en la comunidad sorda.

- Costumbres sordas, no oyentes.

- Barreras de comunicación en la comunidad sorda.

- Habilidades sociales y epistemología sorda.

2. [...] "acuñé el término CODA - Hijos de adultos sordos- que se refiere a los hijos oyentes de padres sordos. Las investigaciones han demostrado que aproximadamente el $90 \%$ de los niños nacidos de padres sordos son oyentes. [...]. Mi vida se movía entre el mundo sordo y oyente. Me sentía cómoda en ambos, pero no me sumergía completamente en ninguno de los dos. El mundo CODA se convertiría en mi tercera opción donde sentí el equilibrio entre mis experiencias culturales sordas y oyentes". (Millie Brother, fundadora de CODA International) 
- $\quad$ Construcciones identitarias de las personas sordas.

- Identidad sorda individual y colectiva.

- Papel de la lengua de signos en la construcción de la identidad sorda.

- Relación entre la cultura e identidad sorda.

\section{Acercamiento al colectivo de personas sordas desde una perspectiva sociocultural}

La evolución histórica de la concepción de la sordera por el propio colectivo (perspectiva emic) y por la sociedad oyente mayoritaria, ha recorrido un largo camino desde la consideración de esta alteridad como "anormalidad", pasando por una perspectiva médico-rehabilitadora que pretendía "normalizar", "curar" y/o "educar", hasta una perspectiva sociocultural en la actualidad. "El modelo cultural (o lingüístico o funcional) despatologiza la sordera al ver a las personas sordas como un grupo minoritario lingüístico y cultural dentro de una sociedad oyente, marcado por la diferencia en lugar de la limitación”. (Wright y Reese 2014:276).

Así, es habitual encontrar que en la sociedad oyente se emplea con frecuencia el calificativo "sordomudo", terminología que deriva de la consideración de la sordera como "anormalidad" o "discapacidad", y que en el uso común se emplea para referirse a personas "sordas de nacimiento", esto es, prelocutivas, cuya sordera se produce antes de la adquisición del lenguaje. Este grupo mantiene una diferente categorización con respecto a las postlocutivas, que han adquirido el lenguaje y con posterioridad han presentado una pérdida de la función auditiva.

Woodward (1972), acuña la distinción entre D/deaf y d/deaf, Sordo vs sordo, para distinguir la construcción cultural de la circunstancia médica. Así, desde un punto de vista emic, las personas sordas no tratan la pérdida auditiva como discapacidad, si no que la transforman en una diferencia positiva bajo la cual ha surgido una lengua propia generadora de una cultura e identidad sordas. Con respecto a la terminología que emplean para autorreferenciarse, cuando realicé mi investigación reivindicaban el uso de las mayúsculas: "Personas Sordas". Si bien, esta consideración no servía para distinguir la circunstancia médica de la cultural, pues para ellos y ellas la primera de estas perspectivas no debería ni siquiera contemplarse, sino más bien, se usaba como una forma de enfatizar su protagonismo. Incluso con independencia de que nos ubicásemos en un contexto médico, hablaríamos de niveles de pérdida auditiva, por ejemplo, de la persona sorda - ser sociocultural - . Por lo tanto, a lo largo de este artículo, utilizo el término en minúscula pues es como el colectivo ha decidido recogerlo en sus comunicaciones y webs del movimiento asociativo, siendo el uso "Persona Sorda" algo que parece reducido, de momento, al ámbito informal.

Ladd (2003), propone un término que considera más adecuado para alejarse de las viejas concepciones médicas de tratamiento de la sordera y que podría traducirse como "sorditud" (traducción propia):

Las ideologías actuales sobre las personas sordas se caracterizan por el término sordera (Deafness). Recientemente ha habido insatisfacción en algunos sectores de la comunidad sorda con este término, ya que tiene una orientación médica. Con el fin de crear un espacio dentro del cual las propias concepciones de los pueblos sordos puedan ser situadas y examinadas, se necesita otro término, y esto lo he designado como Deafhood. (pp.81). 
En mi investigación he comprobado en múltiples ocasiones que el término con el que desea ser visibilizado el colectivo es simplemente el de persona sorda. Dentro de la comunidad suele estar reservado para las personas prelocutivas, mientras que a las postlocutivas, dependiendo de su nivel de pérdida auditiva y de sus distintos grados de identificación como personas sordas profundas, suelen ser referenciadas como hipoacúsicas.

En sus historias de vida, cuentan a modo de narración de toma de conciencia de la diferencia, cómo se les prohibía que configuraran su propio lenguaje a través del cuerpo - desde una perspectiva etic, podríamos hablar del nacimiento del mito fundacional del colectivo como grupo étnico a través de estas experiencias comunes compartidas con la lengua de signos como fuerza motriz-. Desde entonces, han conquistado esferas de identidad erigiéndose como comunidad, se ha comprobado que su lengua, efectivamente lo es. Las personas sordas siempre lo supieron, pero el comienzo de la "concesión" de esta realidad comenzó a dar sus primeros pasos en los años 60 cuando William Stokoe (2005), publica su obra Sign Language Structure, en la que demuestra que las lenguas de signos son lenguas naturales, que poseen las mismas características lingüísticas que las lenguas orales. Morales, E. (2006), recoge cómo se han confirmado las diferentes hipótesis y teorías de diversos autores sobre cómo la lengua de signos cumple los mismos preceptos que las lenguas orales en los cuatro campos estudiados, a saber: procesamiento, adquisición, bases neurológicas y análisis gramatical.

Rodríguez (2013) relata cómo la reafirmación del colectivo, con respecto a su lengua, cultura e identidad, comienza a llamar la atención en el ámbito académico, surgiendo así en los años 70, los llamados "Deaf Studies”, principalmente en Estados Unidos. Las líneas de investigación se dirigen a aumentar el conocimiento sobre su organización e identidad desde una perspectiva emic. En la actualidad, los Deaf Studies "hacen referencia a la experiencia colectiva compartida de ser sordo y de formar parte de la comunidad sorda" (Rodríguez, 2013:15).

El grueso de sus reivindicaciones se dirige a la supresión de las barreras de comunicación que dificultan su día a día en las interacciones con la sociedad oyente: "el oralismo exclusivo niega la necesidad de que el cuerpo sordo tenga un fácil acceso a la comunicación visual” (LeMaster 2003:156). Las personas sordas han sufrido y sufren aún situaciones de dependencia socialmente exigida. La figura del intérprete de lengua signos ha sido uno de los logros históricos más importantes para el colectivo. Esta figura y su importancia, aún es fuertemente incomprendida entre las personas oyentes de fuera de la comunidad. Antes de la existencia del intérprete de lengua de signos, solían ir acompañados y acompañadas por un familiar que se encargaba de comunicarse con el personal sanitario, profesorado, etc. en definitiva, cualquier gestión e interacción de la vida diaria. Una vez terminaba el encuentro, el familiar "resumía" a la persona sorda lo que acababa de ocurrir. A través del intérprete se produce una comunicación simultánea en tiempo real, este o esta no media, es neutral, emite los mensajes en una y otra lengua como lo haría cualquier traductor. Sin embargo, la sociedad oyente, con demasiada frecuencia, no consigue entender este papel y se dirige al intérprete constantemente como si fuera en calidad "de acompañante que explica" a la persona sorda, negándole a esta su capacidad y protagonismo.

El ámbito educativo, es aún hoy en día uno de los principales contextos en el que las personas sordas dirigen sus esfuerzos para introducir mejoras en el derecho al uso de su lengua. La metodología oralista sigue siendo la predominante en las escuelas, hecho que, desde su propia visión emic, restringe su autoidentificación positiva como personas sordas. 
El hecho de que, salvo excepciones, las personas sordas crezcan en familias oyentes supone un cambio substancial en la forma en que se aprende y transmite la lengua. La mayoría adquiere el idioma fuera de la familia, por lo que la escuela se convierte en la agencia esencial en términos de transmisión intergeneracional. (Cabeza-Pereiro y Ramallo, 2016:16).

Con frecuencia hacen énfasis en que los niños y niñas sordas necesitan un referente sordo. Este concepto de modelo de imitación es muy importante para las personas sordas y frecuentemente abordado en conversaciones casuales y debates sobre la educación inclusiva.

Las maneras de vivir, no se nacen con ellas, se enseñan. A las personas sordas, siempre, hasta ahora, ¿Quién nos enseña? Las personas oyentes. (...) Los sordos crecíamos sin un referente sordo adulto, sin un modelo lingüístico de referencia. (Persona sorda trabajador social, entrevista personal, 31 de marzo de 2015).

A pesar del gran avance que supuso para el colectivo de personas sordas el reconocimiento de la ley de LSE en nuestro país (Ley 27/2007, de 23 de octubre), que reconoce el derecho de las personas sordas a contar con intérpretes de lengua de signos en los centros educativos, la realidad se materializa en una falta de recursos y una incomprensión de las necesidades reales del sordo: "por otro lado, considerando la educación inclusiva bilingüe-bicultural de las personas sordas, se evidencia que aún persisten algunas prácticas hegemónicas del oyente, donde la identidad de la persona y del colectivo sordo aún no tiene cabida" (Nairouz y Cedeño 2014:257).

El enfoque educativo en los centros todavía se encuentra influenciado por una perspectiva rehabilitadora o médica de la persona sorda. El colectivo defiende un modelo bilingüe-bicultural y exige la presencia de asesores sordos, según sus propias palabras, para contar con un modelo, un referente, a través del cual poder ir configurando su identidad sorda desde la niñez.

Producto de sentimientos de rechazo vivenciados como colectivo, de la falta de visibilidad de su cultura, necesidades y de la represión lingüística, en la comunidad sorda han surgido categorías emic tales como "oyentizar" y "audismo" para denominar conductas de resistencia colonial. Se refieren a la existencia de una situación de inferioridad impuesta y a las distintas situaciones de discriminación que sufren, llegando a establecer paralelismos con los procesos de colonización:

Oyentizar quiere decir que la comunidad oyente, su lengua, su forma de ver las cosas, su humor, etc.... nos debemos adaptar a eso. (Persona sorda trabajador social, entrevista personal, 31 de marzo de 2015).

El término "oyentizar" se utiliza para referirse al proceso de asimilación cultural al que consideran que han sido sometidos. No es un término que se emplee en charlas de forma reivindicativa, sus discursos en público no devalúan al oyente si no que se dirigen a intentar que éste tome conciencia de la situación de desigualdad que sufren aún hoy en día. Su objetivo es que se entienda que "la Diferencia debe ser reconocida y aceptada en su justa dimensión, sin ambigüedades, ni hipocresías, sin etnocentrismos ni discursos colonizadores que pretendan cambiarla, encubrirla, disfrazarla o modificarla hasta reducirla" (Morales, 2014:20-21). Las pocas veces que lo he escuchado casi siempre ha sido de una forma distendida, para marcar diferencias entre sordos y oyentes. Estas diferencias, son generadoras de tensiones y distensiones, se tratan de forma muy natural y son objeto tanto de polémica como de chanza. 
En torno a la categoría "audismo" una persona sorda manifiesta:

(...) una forma de audismo: el de las personas de fuera de la comunidad sorda hacia nosotros: por ejemplo, ver que un sordo, no puede, no sabe, no vale, o el hecho de que por ejemplo en los edificios de un hospital, las alarmas sean sonoras, eso es audismo, ¿un sordo no va al hospital? (...). (Persona sorda trabajador social, entrevista personal, 31 de marzo de 2015)

El término audismo, comenzó a usarse hace relativamente poco tiempo entre los miembros de la comunidad objeto de estudio, si bien enuncian que el término no es nuevo. Lo utilizan para referirse a distintas situaciones y formas de discriminación a causa de la pérdida auditiva.

\section{Criterios de adscripción a la comunidad sorda}

El acceso al colectivo de personas sordas se produce en el seno de las comunidades que construyen, por ello, su estudio y conocimiento es fundamental para un abordaje como minoría lingüística y cultural. La comunidad sorda da forma al sentimiento identitario y a la cultura de las personas sordas permitiendo su desarrollo aun viviendo en situaciones de contacto permanente con la cultura oyente mayoritaria.

De León, et al., (2007) describen de la siguiente forma esta convivencia intercultural:

Las personas sordas están inmersas en un mundo que utiliza y maneja otra lengua, un mundo lingüísticamente incompatible con el que es imposible generar una comunicación, pero con el que debe necesariamente interactuar, por eso los sordos son personas biculturales. De allí la importancia de la comunidad sorda como espacio de referencia para el desarrollo de identidad y su propia lengua. (pp.3).

Siguiendo a Morales (2008:118) “(...) La pertenencia a dicha comunidad se define por el uso de la lengua de señas, como lengua natural y primera lengua, así como por los sentimientos de identidad grupal que poseen como sordos". Desde el punto de vista emic, definen a la comunidad sorda como la conformada no sólo por personas sordas o hipoacúsicas - personas con una pérdida auditiva de variable intensidad-, sino también personas oyentes y familias de personas sordas que mantienen una vinculación e interacción con el colectivo por diferentes motivos -identificación y/o pertenencia, motivos personales, profesionales, etc. - . Lo que les permite formar parte de la comunidad es principalmente el empleo y conocimiento de la lengua de signos, pero también el respeto por sus valores, cultura e identidad. El nivel de implicación se evalúa en función del manejo e interiorización de su lengua, el conocimiento sobre el colectivo, la participación activa en sus celebraciones, la defensa de sus reivindicaciones, estableciendo niveles de mayor/menor inclusión/ exclusión dentro del grupo. Así, una persona hipoacúsica, puede aprender su lengua, defender los mismos intereses y manifestar sentimientos de identificación y pertenencia, pero hay siempre un límite, una barrera que le separa de la persona sorda prelocutiva. Esto se debe a que esta última, construye el mundo bajo una perspectiva puramente visual porque no tiene memoria auditiva. 
La comunidad sorda, es para las personas sordas, un valor en sí mismo. Para ellos y ellas es un sentimiento de unión, una fuerza solidaria que se materializa en objetivos comunes, en una cosmovisión compartida y en una empatía hacia su cultura, formas de ser y hacia su legua, es ante todo un sentimiento real.

Las personas afectadas sienten un apoyo ideológico, el apoyo del grupo, quieren luchar, compartir las necesidades diarias, pero ojo, la lucha de la comunidad sorda, no es sólo para las personas sordas es una lucha para las dos, la oyente también (...). La comunidad es un valor (...). (Persona sorda profesor de LSE, entrevista personal, 22 de marzo de 2015).

Se hace énfasis en una evolución del sentimiento de rechazo hacia una apertura de la comunidad a nuevos oyentes interesados por su lengua y prácticas culturales. Este nuevo enfoque del colectivo supone una estrategia adaptativa fuerte, en el sentido de que son conscientes de que en la visibilidad de su diferencia en la sociedad mayoritaria se hallan las posibilidades de consecución de sus objetivos.

La comunidad sorda puede parecer cerrada pero no lo es, debemos entender que las personas sordas han sufrido mucho, la sociedad ha intentado que desapareciéramos, que nos extinguiéramos, esto genera un sentimiento fuerte de resistencia. En ese sentido ha habido una evolución, hace 15 o 20 años venían oyentes y era... ¿tú qué haces aquí? Ahora es ¡Ah! ¿Vienes a aprender lengua de signos? ¿Te interesa contactar con nosotros? Bienvenido” (Persona sorda trabajador social, entrevista personal, 31 de marzo de 2015).

Las personas sordas coinciden en sus percepciones sobre los criterios mínimos de adscripción en su comunidad. En primer lugar, resulta imprescindible el conocimiento de la lengua de signos a un nivel alto de competencia. El respeto y puesta en valor de su identidad, lengua, cultura y la implicación en sus actividades y reivindicaciones son igualmente importantes. Lo que caracteriza el lazo de unión de la comunidad, concepto más amplio en el que se incluyen además de las personas sordas, las personas oyentes vinculadas por diferentes motivaciones, es sin duda, la defensa de la lengua de signos. Diferencian como categoría emic el "colectivo de personas sordas" en el que se incluyen sólo miembros con pérdida auditiva de variable intensidad, del de comunidad que acabamos de describir.

(...) Para la integración del oyente este debe saber lengua de signos. La comunicación debe ser directa, sin intermediarios, sin barreras de comunicación (...). (Persona sorda profesor de LSE, entrevista personal, 22 de marzo de 2015).

Una vez adquiridas las condiciones mínimas para lograr un proceso de inclusión satisfactorio, lo que se desprende de la observación participante y de los testimonios de los nativos, es que para que se produzca una adscripción real, se debe entender a la comunidad como familia y red de apoyo solidaria. Además, la percepción de los miembros debe ser la de que la persona interesada en formar parte posee un interés real en el colectivo fruto de un proceso de identificación empático no utilitarista.

(...) ¿Por qué nos sentimos mal? Las personas oyentes vienen y se van, las personas sordas nunca se van, las personas sordas se quedan, toda la vida, hasta que se mueren. Un oyente abre una puerta, la cierra y se va. Las personas sordas se hartan, parece un zoo. Como si estuviéramos en una jaula. (...). (Persona sorda profesor de LSE, entrevista personal, 22 de marzo de 2015). 
El proceso de inclusión en la comunidad de la persona hipoacúsica impone normas de adscripción más duras. Al respecto, he observado desde la inclusión real a través de la desvinculación con características oyentes (interacciones empleando la lengua oral sin hacer uso de la lengua de signos, acciones donde se visibiliza el aprovechamiento de restos auditivos como ver la TV sin subtítulos, etc.), pasando por identidades múltiples de semi-incorporación y fluctuación entre ambos mundos. Estos casos se producen por una falta de identificación completa con uno $u$ otro grupo. En ocasiones presentan una escasa competencia en lengua de signos, otras veces la falta de identificación toma un cariz más cultural y no llegan a interiorizar la cultura sorda como propia al mantener prácticas más asociadas al mundo oyente:

La percepción por parte del colectivo sordo de la existencia de una identificación y pertenencia reales se convierte en un imperativo para ellos y ellas:

Vemos a los hipoacúsicos igual que un columpio, ahora con oyentes, ahora con sordos, los sordos queremos que escojan una forma de vida, o sorda u oyente, nada más. (...). (Persona sorda trabajador social, entrevista personal, 31 de marzo de 2015).

En los testimonios de las personas sordas se muestra un duro rechazo a la utilización de la comunidad con fines estratégicos:

(...) a las personas hipoacúsicas el proceso de identificación como sordo les cuesta mucho (...). (...). El problema es que a veces, el objetivo no es el interés real, quieren aprovecharse, encontrar un puesto de trabajo, como una estrategia. (...) Para integrarse deben comunicarse bien con nosotros, entender que los sordos somos una familia que le da una cultura. (Persona sorda líder de la comunidad, entrevista personal, 5 de marzo de 2015).

En cuanto a la opinión de las personas oyentes, así resume una de las CODA entrevistadas, los requisitos imprescindibles para formar parte de la comunidad sorda:

Para ser miembro de la comunidad sorda debes ser aceptado por las personas sordas, mostrar respeto por ellas, nunca robarles el protagonismo, mantenerte en un segundo plano en determinadas ocasiones y echarles una mano cuando lo soliciten. (CODA número 2, cuestionario abierto, 13 de febrero de 2015).

He observado como las personas oyentes que pertenecen a la comunidad empatizan con las situaciones de discriminación y dominación que han sufrido las personas sordas a lo largo de su historia e intentan mantenerse en un segundo plano cediéndoles el protagonismo, si bien, a veces, estas tensiones son fruto de controversias. Un ejemplo de este límite de adscripción grupal es que, en el movimiento asociativo, las personas oyentes socias tienen voz, pero no voto. De este modo se asegura que el surgimiento y consolidación de liderazgos, la esfera de las decisiones político-reivindicativas y de representación del colectivo, quede reservada exclusivamente a las personas sordas. 
5. Mismidad y otredad: choques culturales y epistemología sorda

La presencia de comportamientos específicos del colectivo que producen situaciones de choque cultural en "el otro" mantienen un límite entre el "nosotros" y el "ellos" que los define como organización social y a la vez limita a los oyentes de la comunidad formar parte al mismo nivel de intensidad. Al ser preguntadas sobre posibles "características específicas" y "choques culturales" las personas oyentes señalan la percepción de diferencias en estilos comunicativos poco asertivos, cosmovisiones distintas otorgando mayor importancia las personas sordas a otro orden de cosas tales como: costumbres, celebraciones, actos conmemorativos y prácticas culturales como el humor sordo o manifestaciones artísticas incorporadas.

Valoran mucho las costumbres, hasta el punto de que a veces no se plantean que, aunque ya no le gusten a nadie, se puedan modificar. Son muy protocolarios en ese aspecto. (ILSE, cuestionario abierto, 4 de febrero de 2015).

Me choca el valor y respeto que confieren a sus costumbres y tradiciones, se las toman muy en serio, si hay que celebrar una fiesta o acto honorífico, es extremadamente importante para ellos. (CODA N¹, cuestionario abierto, 13 de febrero de 2015).

Otro tipo de choques culturales se producen por las distintas visiones que mantienen personas sordas y oyentes entre sí. Es un prejuicio muy extendido entre los oyentes tanto de dentro como de fuera de la comunidad, calificar a las personas sordas como desconfiadas.

Estamos cansados de que digan que somos desconfiados, ¿qué pasa? ¿No hay oyentes que lo son? Hemos sufrido mucho con las etiquetas, incluso hoy en día entramos en una tienda y nos miran raro, nos siguen como si fuéramos a robar. (Persona sorda líder de la comunidad, entrevista personal, 5 de marzo de 2015).

Sí creo que son desconfiados como consecuencia de las carencias comunicativas a lo largo de su vida. No poder acceder a información que te rodea, que no te expliquen las cosas que se hablan en tu casa provocan que un individuo se sienta desplazado y se convierta en desconfiado. (ILSE, cuestionario abierto, 4 de febrero de 2015).

Depende, no siempre es así - desconfiados-. Con frecuencia son inocentes y confiados en exceso. Observo, eso sí, que tienden a confiar en las personas sordas mucho más que en las oyentes. (CODA №2, cuestionario abierto, 13 de febrero de 2015).

Las personas oyentes lo entienden como consecuencia de las barreras de comunicación, si bien, dentro de la comunidad éstas no deberían darse al hallarse en una situación de igualdad comunicativa. La desconfianza hacia el oyente dentro de la comunidad no es tanto comunicativa como actitudinal: con respecto a las mejores o peores intenciones con las que este se interesa por ellos y ellas, así como por la posibilidad de pérdida de esferas de poder por su intromisión en asuntos que ellos deben manejar.

Las carencias educativas que sufren, por múltiples factores que no vamos a analizar aquí, sumadas a las experiencias colonizadoras, crean en el colectivo una doble reacción contradictoria, por un lado, ciertas inseguridades les hace buscar el apoyo del oyente, mientras que por el otro ponen en valor su cultura en detrimento a la mayoritaria, tendiendo a apoyar con mayor facilidad el discurso de una persona sorda ante una controversia y, sobre todo, le otorgan más confianza interpersonal. 
Un sordo le dice a otro sordo un descalificativo, por ejemplo, el sordo no hace caso porque sabe que no se lo dice con mala intención, en cambio, si un oyente le descalifica se siente mal, se acompleja, no eres de mi cultura, eres de fuera, pero depende de que oyente se trate, es diferente si es un oyente aceptado en la comunidad. (Persona sorda trabajador social, entrevista personal, 31 de marzo de 2015).

Otra de las etiquetas que se suelen asociar a las personas sordas dentro de la comunidad es el de emplear un estilo comunicativo particular, brusco y poco asertivo. La manera directa sin adornos ni rodeos para introducir temas de conversación u obtener información, se materializan en un choque cultural que incomoda al oyente:

Me llamó la atención que de primeras me hiciesen un interrogatorio completo y sin mucho decoro: cómo te llamas, porqué este signo ${ }^{3}$, dónde estudias, de dónde eres, tienes hermanos, estás casada, tiene novio, dónde está, de que trabajas... prácticamente a la media hora de verme por primera vez. Y si alguno se acercaba, al poco, ese mismo informaba al otro delante de mis narices como si ya me hubiese ido. (ILSE, cuestionario abierto, 4 de febrero de 2015).

(...) Creo que su idea de lo correcto y de los buenos y malos modales es distinta. (CODA №2, cuestionario abierto, 13 de febrero de 2015).

A lo que no me acostumbro es a la invasión de la intimidad a la que suelen tender las personas sordas con sus preguntas, aunque no te conozcan de nada. (CODA N² 2 , cuestionario abierto, 13 de febrero de 2015).

La perspectiva sociocultural, considera que las personas sordas, por el hecho de serlo, comparten una especial y/o distinta forma de percibir las cosas:

Uno está esencialmente en busca de una epistemología sorda, es decir maneras sordas de estar en el mundo, de concebir ese mundo y su propio lugar dentro de él (tanto en la realidad como en la potencialidad). Resultará que un aspecto crucial de esa epistemología es que no es simplemente de oposición, sino que examina y presenta la naturaleza y el significado de las relaciones entre los pueblos sordos. (Ladd, 2003:81).

Los oyentes tienden a calificar estas "maneras distintas" a falta de habilidades sociales atribuibles a modelos comunicativos en la familia, escuela, en donde sufrían fuertes carencias comunicativas con las que transmitir pautas. De esta manera, la esfera normativa, quedaría relegada a cuestiones básicas, superfluas, que no permitían profundizar en fórmulas correctivas:

Las familias muchas veces no se han parado a educar por la falta de comunicación fluida, y se han limitado a entenderse en aspectos muy básicos relacionadas con actividades cotidianas y básicas: comer, aseo, enfermedades. (ILSE, cuestionario abierto, 4 de febrero de 2015).

Pero al margen de estas supuestas carencias comunicativas, hemos de tener en cuenta también la naturaleza de la lengua de signos en las interpretaciones que hacemos sobre determinadas conductas los oyentes y que recibimos como bruscas.

3. Se refiere al signo autodefinitorio, el apodo en lengua de signos consistente en una seña que caracteriza al bautizado pudiendo versar sobre una característica resaltable, física o personal. 
Wright y Reese (2014), ilustran de esta forma las peculiaridades de la lengua de signos en un contexto sanitario en la comunicación entre el terapeuta y el paciente sordo:

La ASL ${ }^{4}$ es tradicionalmente más directa que el idioma inglés. (...). Por ejemplo, un cliente oyente puede "bailar alrededor del tema" o "andar por las ramas" en su respuesta a la interpretación del terapeuta. ${ }^{5}(. .$.$) . Un cliente sordo$ en la misma situación puede responder más directamente. (...). Los terapeutas pueden no estar preparados para respuestas tan detalladas o altamente descriptivas. Se pueden sacar conclusiones inexactas, una comunicación directa mal entendida o información importante etiquetada como "divagaciones" por los terapeutas con una visión etnocéntrica (p. 282).

La traducción de lenguas de signos a lenguas orales presenta un trabajo traslativo cultural más evidente que en los casos de otras lenguas. Los mecanismos cognitivos activados durante la transferencia encuentran una mayor dificultad en la fase previa al output correspondiente a la traducción cultural. El proceso de interpretación exige al intérprete de lengua de signos un conocimiento previo profundo de la cultura sorda para poder dotar de sentido la información procesada. En algunos casos, a causa de polisemias, o debido a diferencias en los niveles morfológico, sintáctico y semántico se presentan problemas de intraducibilidad como por ejemplo en el intento de transferencias relativas a contenidos humorísticos o irónicos.

Desde una perspectiva etic, podemos contemplar que, en ciertos contextos comunicativos, la percepción de que las personas sordas poseen menos habilidades sociales sin tener en cuenta la influencia de la estructura de la lengua de signos y su potencial expresivo incorporado, pueden dar como resultado juicios etnocéntricos sobre "cómo deben ser" o "comportarse" materializándose estas interpretaciones en un ejercicio de asimilación cultural. El acceso al conocimiento se produce en las personas sordas a través de una lengua puramente visual y en contextos sociales en los que la información les resulta intransitable. Estas situaciones producirán experiencias totalmente diferentes a las oyentes que definirán sus formas de ser y comportamientos y se traducirán en una producción de conocimiento particular del colectivo. Hablamos de la existencia de una epistemología sorda.

\section{Construcción y consolidación de la mismidad: lengua, cultura e identidad sordas}

El potencial de la lengua de signos, como generadora de identidad, tiene que ver con su carácter diacrónico a través de las experiencias similares - aunque variables- de restricción o incluso prohibición en su uso a lo largo de la vida de las personas sordas. La lengua de signos se convierte así en un mecanismo de conformación de la identidad desde edades muy tempranas:

Una de las características más relevantes de las minorías étnicas, culturales y lingüísticas es la existencia de una lengua propia del grupo. Las personas sordas se comunican a través de la lengua de signos y esto supone desarrollar una identidad específica (Pérez de la Fuente, 2014:277).

4. American SignLanguage

5. Traducción propia del término en inglés "counselor". 
Así respondía una persona sorda al ser preguntada por su identidad:

Yo miro hacia dentro de mi (traducción literal del signo que indica un autoanálisis reflexivo) y lo relaciono con mis manos, la lengua de signos. (Persona sorda líder de la comunidad, entrevista personal, 5 de marzo de 2015).

La lengua es utilizada como "rito de paso" de acceso a la comunidad que se inicia con el "bautizo" otorgando un apodo consistente en una seña que describe un aspecto físico o personal del bautizado. Las personas sordas utilizan su lengua en este sentido para integrar en su comunidad a personas no conocedoras de la lengua de signos. Es una prueba fundamental, no sólo el hecho de conocerla si no de emplearla adecuadamente, entenderla y sobre todo llegar a usar "correctamente" su valor simbólico y metafórico.

Skliar (1997) planteaba un concepto de cultura sorda basado en la relación de ésta con la lengua de signos, así como con procesos identificativos de experiencias comunes de marginación. Estas experiencias, definidas como "sufrimiento" dan solidez a los vínculos entre personas sordas dotando de forma y contenido al concepto de cultura sorda universal.

(...) La cultura sorda es una fusión, quiero decir, es como la arena, es raro, es difícil de ver o atrapar, pero está dentro. Cómo explicas que una persona sorda se va a un país extranjero y ¡es la misma cultura! ¿Cómo viene?, ¿cómo surge?, no es una obra, es una cultura visual que nos afecta por igual, el mismo sufrimiento.... (Persona sorda profesor de LSE, entrevista personal, 22 de marzo de 2015).

A pesar de que existen variaciones culturales entre los grupos de personas sordas en el mundo, fruto de las interacciones y adaptaciones intergrupales con otras organizaciones sociales en su área ecológica, las personas sordas mantienen la existencia de una cultura sorda universal. Esta cultura trasciende el problema temporal puesto que se fundamenta en una percepción visual del mundo consecuencia del hecho biológico de ser sordo. Éste seguirá existiendo con independencia del momento histórico en el que analicemos su forma de organización social, así como de las posibles estrategias de adaptación utilizadas en el locus en el que el grupo se desarrolla. Estas consideraciones sientan las bases para un posible estudio transcultural de las comunidades sordas.

He observado que la lengua de signos y sus implicaciones cognitivas en el pensamiento de la persona sorda junto con el autoconcepto de la diferencia, se articulan como generadores de cultura, tanto a nivel de influencia en formas de ser y comportamientos específicos del colectivo -normas, costumbres, rituales, valores- como de prácticas culturales -manifestaciones y expresiones artísticas-. En la transmisión de la cultura a través de la lengua, puede observarse la cultura misma. La cultura sorda parece construirse bajo la materialización en formas de ser, comportamientos, rituales, costumbres, valores, normas y prácticas culturales propias de las personas sordas derivadas de la presencia de una epistemología sorda transmitida e incorporada a través de la lengua de signos.

En cuanto al abordaje de la identidad sorda, no fue fácil durante las entrevistas en profundidad, el planteamiento en conversaciones causales y en la utilización de cuestionarios reflexivos. Aunque es frecuentemente aludida, convirtiéndose en tema principal de encuentros y jornadas para debatir sobre ella, en su tratamiento del concepto al ser interpelados por su significado, tanto personas sordas como oyentes saluden más bien a un compendio de prácticas culturales que definen una forma de ser colectiva: ubicación 
en los espacios para el máximo aprovechamiento visual, formas de saludo y cortesía, valor dado a las tradiciones, etc. "Las identidades son producidas por el juego interior entre el organismo (conciencia individual y reflexión) y la estructura social, reaccionando sobre esta última, ya sea manteniéndola, modificándola o reformándola" (Hola et al., 2004:67). Al reflexionar sobre los procesos identitarios, las personas sordas distinguen sus individualidades de una identidad colectiva que pretende, entre otras cosas, lograr un impacto que alcance una representación de sus intereses como colectivo sobre la estructura social oyente.

Primero, tú construyes tú identidad individual que surge poco a poco, después entrando en contacto con otras personas sordas, ves intereses y afinidades comunes y surge esa identidad grupal (...). La persona oyente tiene su identidad, tiene 5 sentidos, no es consciente de ello, es un cuerpo completo, puede escuchar todo. La persona sorda es consciente de que le falta uno, de que no puede oír, y esto afecta a todo...Para que la identidad esté dentro se construye una cultura a través de una percepción visual del mundo, de una lengua de signos, es un proceso natural. (Persona sorda profesor de LSE, entrevista personal, 22 de marzo de 2015).

La construcción de una identidad colectiva se evidencia en las distintas dimensiones que configuran su comunidad como propia y distintiva.

Al plantear la cuestión identitaria a las personas entrevistadas, han relatado parte de su historia de vida, experiencias relacionadas con su toma de conciencia de ser sordo desde edades tempranas y una búsqueda del - yo igual- que culmina al encontrar su grupo de iguales sordos. Describen procesos similares de negación, aceptación y de angustia ante la pregunta: ¿Seré yo solo así en el mundo? Esta pregunta reflexiva nos permite identificar la existencia de una identidad sorda en construcción previa al contacto grupal en la que se incluyen dimensiones negativas relacionadas con la percepción de la diferencia y la restricción, de menor o mayor grado según cada caso, en el uso de su lengua.

La percepción de la construcción de la identidad de las personas sordas se muestra indisociable de la oposición a una alteridad oyente que ha minusvalorado al colectivo:

Yo no soy peor que tú - oyente- (...). La identidad es la descripción de mí mismo. La identidad sorda implica la pertenencia a un grupo con unos intereses comunes, problemas, objetivos, cultura, vivencias comunes. (Persona sorda trabajador social, entrevista personal, 31 de marzo de 2015).

La producción antropológica en España, con relación a la identidad, se centró en su momento, en el debate alrededor de la concepción de ella misma como un fenómeno sustantivo, esencial o primordial en oposición a una visión instrumental. Siguiendo a Prat i Carós (1999) hablando sobre esta doble concepción sobre la identidad:

(...) en el primero, la identidad se concibe como una "herencia" y se trata siempre de algo estático, permanente, fijo e intocable. (...) En el polo opuesto, hay otro discurso en el que la identidad aparece como proyecto o estrategia para construir un nuevo tipo de sociedad civil (...). (pp.23).

Autores como Geertz (1973) defendieron enfoques primordialistas, considerando a las culturas como estructuras homogéneas en su interior, rígidas, modeladas por grupos unidos por lazos de solidaridad. Esta perspectiva fue criticada por su carácter inamovible, tampoco parecía dar cuenta de la etnogénesis ni de la consolidación y transformaciones que tenían lugar en estas identidades. 
Las teorías sobre identidad han estado histórica e inevitablemente relacionadas con las de etnicidad e identidad étnica, Motta (2006) reflexiona sobre la propuesta interaccionista en oposición a los enfoques primordialista e instrumental:

(...) Una posición intermedia en Europa es la planteada por Frederik Barth con el concepto de Fronteras Étnicas, según este autor, las características étnicas no se derivan de las características intrínsecas de una colectividad social, sino más bien de fronteras socioculturales entre diferentes colectividades. Las distinciones étnicas se visualizan en esta frontera, de la cual los "marcadores étnicos" subrayan las diferencias culturales entre los grupos. (pp.7).

Por su parte, el constructivismo:

(...) se pregunta por los específicos y localizados procesos no discursivos y discursivos de la producción de la diferencia étnica; esta no aparece como un fenómeno natural de la condición (biológica o cultural) humana sino históricamente localizado, producto de un arduo proceso de mediaciones y confrontaciones en el espacio social. (...). Una posición constructivista es anti-esencialista porque cuestiona la necesaria correspondencia entre aspectos o planos de la vida social (Restrepo, 2004: 30-31).

Desde un punto de vista emic, la identidad de las personas sordas se conforma como una realidad objetivada en prácticas, discursos y representaciones colectivas que ellos identifican como propios. Desde un punto de vista etic, la identidad opera como un constructo científico con el que referirnos a la amalgama de significados implícitos en esas prácticas. García García (1999) encuentra que ideas, conocimientos, sentimientos y conductas estos tres elementos que considera operan en la identidad, se encuentran articulados en lo que podríamos llamar "proyecto" en el que los procesos de identificación pueden observarse en el presente y en el futuro. Más allá de una visión instrumental en el sentido utilitarista, presente y necesaria para una consecución de protagonismo político y social que redunde en una mejora de la calidad de vida de los miembros de la comunidad sorda, se han observado lazos de altruismo, cooperación y solidaridad en la conformación identitaria grupal del colectivo de personas sordas propios de la concepción de su comunidad como familia y red de apoyo.

Las personas sordas otorgan muchísima importancia a la implicación solidaria y altruista en las actividades, lucha por las mejoras y reivindicaciones como colectivo, la colaboración en la organización de las celebraciones y eventos, etc. Pero a cambio, consideran a los miembros de su comunidad como una familia. Así contestaba una persona sorda a la pregunta de cómo puede lograr una inclusión satisfactoria en su comunidad una persona hipoacúsica:

"Debe comunicarse bien con nosotros, entender que los sordos somos una familia que le da una cultura". (Persona sorda líder de la comunidad, entrevista personal, 5 de marzo de 2015).

Por su parte, el concepto de identidad definido por la propia inmutabilidad de las categorías a las que se adscribía tales como etnia o discapacidad, se utilizó en su momento para dar forma y contenido a las identidades de los grupos sociales que se autoidentificaban con ellas:

La política cultural durante los años ochenta y noventa ha estado más centrada en categorías de gente que, superficialmente, son muy diferentes de los grupos de inmigrantes, los nativos americanos o los negros 
americanos, grupos definidos por el género, por ejemplo, la orientación sexual, las minusvalías o las creencias religiosas. (Kuper, 1999: 273).

Sin embargo, la irrupción de "la posmodernidad deja las raíces en el aire...en las ondas, en la web. Los definidores tradicionales de identidad - raza, género, clase, estatus, sangre, origen, etc. - pierden consistencia en la condición posmoderna" (Bermejo 2011:10). Caracterizada por su carácter profundamente antifundamentalista y antiesencialista, la posmodernidad cuestiona los metarrelatos al modo Lyotardiano y las verdades absolutas, en consecuencia, las identidades fijas se convierten en múltiples, flexibles, efímeras, propias de un mundo cambiante, contingente y globalizado. En este contexto:

Las condiciones para que un retorno a la comunidad y de la comunidad (tradicional) fueran efectivas deberían ser, por un lado, homogeneidad de creencias, valores y pautas; y, por otro, relaciones personales directas, intensas y continuadas -algo que resulta imposible en sociedades tecnológicamente avanzadas o en vías de tecnificación, proceso que parece imparable (Bermejo, 2011:55).

Sin embargo, en los grupos de personas sordas, se observa una continuidad de la comunidad tradicional, en tiempo real, con una comunicación cara a cara, presencial, convirtiendo a las asociaciones en el locus donde la identidad y etnicidad se afianzan y al mismo tiempo, estas se ven reforzada por el uso de las NNTT que permiten crear vínculos transfronterizos donde la comunicación ya no constituye una barrera, si no un mundo de posibilidades. Asimismo, se observa cierta homogeneidad alrededor del continuismo de sus costumbres y "formas de ser típicamente sordas" así como en su valor por antonomasia: la conservación y difusión de su lengua. En este sentido, desde un punto de vista etic, se constituyen en un movimiento revitalizado como puede ocurrir con los nacionalismos o con el feminismo en nuestro siglo. El comunitarismo, que la posmodernidad puede considerar obsoleto e ineficiente, continúa siendo fructífero para los movimientos por los derechos de las personas sordas. El locus asociativo funciona, así como un espacio real, no virtual, en el que dar solidez a una identidad no alterada por los procesos sociales cambiantes en este aspecto concreto de la cosmovisión visual.

La categoría identidad, para ellos y ellas, continúa siendo útil como constructo para sus intereses grupales. Aunque las características personales, la esfera reservada a las identidades individuales, se ve igualmente moldeada por los procesos cambiantes propios de las sociedades plurales globalizadas, hay un aspecto que les define que permanecerá inalterado: la percepción visual del mundo.

\section{Conclusiones}

Con este trabajo, he realizado un acercamiento a la comunidad sorda presentando descripciones de la vida interna del colectivo de personas sordas desde una perspectiva emic junto con otra etic posterior empleada para categorizar y analizar los fenómenos observados. El fin último es ampliar el conocimiento sobre esta minoría lingüística y cultural para facilitar una exitosa intervención social. 
La producción de categorías emic tales como "oyentizar" y "audismo" son ejemplos de la percepción de carencias por parte de las personas sordas en el modelo de incorporación social actual. Podemos extraer las siguientes conclusiones en relación con las debilidades que deben superarse para caminar hacia la incorporación social de las personas sordas en mayores condiciones de igualdad:

- Para superar el modelo patológico en todos los ámbitos, social, médico, educativo, político-social, etc. debe adoptarse el modelo que se defiende desde las asociaciones, federaciones y confederaciones de personas sordas: el bilingüe. El modelo a defender es intercultural porque las personas sordas viven inmersas en dos culturas.

- Sólo a través de una implicación y conocimiento de sus características socioculturales, de la comprensión de su mundo simbólico, pueden los y las profesionales de la intervención social lograr el éxito en su acompañamiento del empoderamiento de las personas sordas.

- Tras el análisis de los resultados, para el que ha resultado útil la postura interaccionista que permite acceder al fenómeno étnico estableciendo los criterios de adscripción y autoadscripción al grupo, puedo concluir que la comunidad sorda está definida por una serie de criterios de pertenencia y límites de acceso a la misma. En cuanto a los criterios mínimos de pertenencia y adscripción a la comunidad sorda encontramos: el conocimiento amplio de la lengua de signos, el respeto y puesta en valor de su identidad, lengua y cultura, así como la implicación en sus actividades y reivindicaciones. El oyente añade la necesidad de relegarse a un segundo plano cediendo el protagonismo a la persona sorda. En un nivel más profundo de análisis, observamos que resulta imprescindible la consideración de la comunidad como familia y red de apoyo solidaria y la percepción por parte de sus miembros de las intenciones nobles, no utilitaristas del recién llegado.

Los límites sociales, en cuanto a criterios de exclusión que evidencian las personas sordas para establecer la pertenencia a su grupo étnico tomando como referencia sus interacciones con "el otro" oyente extraigo las siguientes conclusiones:

- Existencia de mecanismos inconscientes de alterización: la presencia de comportamientos específicos del colectivo que producen situaciones de choque cultural en "el otro" mantienen un límite entre el "nosotros" y "ellos" que los define como organización social y a la vez permite construir una barrera que impedirá formar parte al mismo nivel de intensidad a aquellos y aquellas que no produzcan y reproduzcan estas conductas. Son las percibidas por el oyente como "chocantes", por. Ej., estilos comunicativos no asertivos; cosmovisiones distintas otorgando mayor importancia las personas sordas a otro orden de cosas tales como, sus valores propios: lengua, identidad, cultura, costumbres; prácticas culturales menos accesibles al oyente como el humor sordo o manifestaciones artísticas incorporadas.

- Puesta en práctica de fórmulas de contención: dentro de la comunidad, son las personas sordas las que ocupan los puestos de poder, las situadas en la arena política y de toma de decisiones.

- Presencia de normas endogrupales rígidas: el nivel de exigencia de implicación y participación en las actividades tanto lúdicas como reivindicativas es alto.

- Al analizar las dinámicas de interacción dentro de la comunidad se observa la existencia de una epistemología sorda: el acceso al conocimiento de las personas sordas se produce entre un contexto de diglosia plagado de barreras comunicativas y una lengua puramente visual, esto implica una construc- 
ción del mundo y un procesamiento de la información distintos. La producción del conocimiento, por lo tanto, también será sustancialmente diferente al del oyente materializándose en formas de ser propias del colectivo.

- Sobre la autogénesis identitaria mi postura no se acerca a la primordialista debido a su abordaje esencialista de la identidad. Los relatos de las personas sordas demuestran que su identidad se constituye como un proceso dinámico y diacrónico que pasa por distintas fases a lo largo de la vida de la persona sorda. La autogénesis tiene lugar con la toma de conciencia de la diferencia y esta experiencia se consolida con el contacto en la comunidad dónde el pasado toma fuerza a modo de "mito fundacional" con el intercambio de experiencias compartidas del hecho de ser sordo. El conexionismo en la construcción de la identidad sorda tiene que ver como la toma de conciencia de la existencia de una interpretación y una comunicación con el mundo diferente y que ellos reflejan en la coincidente pregunta reflexiva: "¿Seré yo así, único en el mundo? y que sería, por lo tanto, previa e independiente del contacto con el grupo de iguales. Las identidades fluidas, efímeras, a las que nos adscribimos, son tan modificables como rápidamente desechables, pero la percepción visual, es un aspecto inalienable de la construcción identitaria de la persona sorda que, aunque cambiante y dinámica, permanecerá indisociable de su identidad.

- Sobre la identidad colectiva puedo decir que es una reafirmación social de la individual, que permite su expansión y desarrollo. Con la incorporación a la comunidad sorda, se inicia un proceso de identificación social y autoadscripción que convertirá las experiencias propias de la toma de conciencia de "ser sordo", esto es, de parte de su identidad individual, en un sentimiento de pertenencia en dónde la diferencia es motivo de orgullo y reivindicación.

- La lengua y la cultura sorda constituyen los pilares básicos que ayudan a conformar la identidad de las personas sordas y a establecer los límites de acceso a la comunidad:

La lengua de signos tiene una importancia vital en la conformación de la identidad de la persona sorda desde edades tempranas que se intensifica a partir de la entrada en la comunidad sorda, desde el "rito de paso" con el apodo o seña autodefinitorio hasta su dominio lingüístico, defensa y protección.

La cultura sorda no se reduce a un compendio de prácticas y producciones culturales, alberga en ella las relaciones intrínsecas y diacríticas entre aquellas y la identidad étnica y lingüística. Responde a comportamientos concretos moldeados a partir de la toma de conciencia de la diferencia y de la percepción visual del mundo. Las limitaciones de acceso a la comunidad con las que se encuentra el oyente se encargan de dar contenido a esa cultura. Hay connotaciones en las interacciones, en los comportamientos, en las formas de ser y en las propias prácticas culturales, que sólo están al alcance de las personas sordas por el hecho de serlo. 


\section{Referencias bibliográficas}

Bermejo, D. (2011). La identidad en sociedades plurales. Barcelona: Anthropos Editorial.

Cabeza-Pereiro, C. y Ramallo, F. (2016). "Lenguas de signos y educación en España. Una aproximación desde la comunidad sorda". LanguageProblems\&LanguagePlanning,40(1), pp. 1-25.

Chavarría, S. (1994). Un cambio de paradigma: La educación de la persona sorda. Recuperado dehttp://www. educoas.org/portal/bdigital/contenido/laeduca/laeduca_119/articulo3/index.aspx?culture=es\&navid=201

De León, A. et al. (2007). Cultura sorda y ciudadanía construyendo identidad(en línea).Recuperado de http://www. cultura-sorda.org/cultura-sorda-y-ciudadania/

De Melo, A. V. (2015). “Children of deaf adults: CODAS em Sergipe”. Interfaces científicas, 3(3), pp. 85-91.

España. Ley 27/2007, de 23 de octubre, por la que se reconocen las lenguas de signos españolas y se regulan los medios de apoyo a la comunicación oral de las personas sordas, con discapacidad auditiva y sordociegas, Boletín Oficial del Estado, 24 de octubre de 2007, núm. 255, pp. 43251-43259.

García García, J. L. (1999). "A identidade cultural: acontecementos, procesos e proxectos”. En M. Portasany (coord.), Galicia fai dous mil anos: o feito diferencial galego (pp. 83-94). Santiago de Compostela: Museo do Pobo Galego.

Geertz, C. (1973). La interpretación de las culturas. Barcelona: Gedisa.

Hola, A. et. al (2004). "Personas sordas e identidad". Extramuros: Revista de la Universidad Metropolitana de Ciencias de la Educación, 3, pp. 66-89.

Kuper, A. (1999). Cultura, la versión de los antropólogos. Barcelona: Paidós.

Kyle, J. (1990). "The Deaf Community: Culture, Custom, and Tradition”. En S. Prillwitz y T. Volhaber, T. (eds.), Sign Language Research and Application (pp. 175-186). Hamburg: Signum Press.

Ladd, P. (2003). Understanding deaf culture: in search of deafhood, Clevedon: Multilingual Matters.

LeMaster, B. (2003). "School Language and Shifts in Irish Deaf Identity". En L. Frances (ed.), Many Waystobe Deaf International Variation in Deaf Communities (pp. 153-172). Washington DC: Gallaudet University Press.

Morales, A. M. (2008). La comunidad sorda de caracas: una narrativa sobre su mundo(en línea). Recuperado de https://cultura-sorda.org/wp-content/uploads/2015/04/Tesis_Morales_2008.pdf

Morales, A.M. (2014). "Nombrando a los otros o el travestismo discursivo en la alteridad". Revista de investigación, 38(83), pp. 15-32.

Morales, E. (2006). Lingüística de las lenguas de signos: perspectiva histórica(vídeo Signado en línea). Recuperado dehttp://www.cervantesvirtual.com/nd/ark:/59851/bmcpkOrO

Motta, N. (2006). Territorios e identidades (en línea). Recuperado de https://dialnet.unirioja.es/servlet/ articulo?codigo $=2362798$

Nairouz, Y. y Cedeño, A. (2014). "Consideraciones pedagógicas para el reconocimiento de la identidad personal y colectiva de las personas sordas”. Revista española de discapacidad, 2(2), pp.255-260. 
Pérez de la Fuente, O. (2014). Las personas sordas como minoría cultural y lingüística(en línea). Recuperado de https://dialnet.unirioja.es/servlet/articulo?codigo $=4834536$.

Prat i Carós, J. (1999). "O tema das identidades na antropoloxía social do estado español”, en M. Gondar, Galicia fai dous mil anos: o feito diferencial galego (pp. 19-50). Santiago de Compostela: Museo Do Pobo Galego.

Ramírez, E. (2011). Etnicidad, identidad, interculturalidad. Teorías, conceptos y procesos de la relacionalidad grupal humana. Madrid: Ramón Areces.

Restrepo, E. (2004). Teorías contemporáneas de la etnicidad: Stuart Hall y Michel Foucault.Popayán: Universidad del Cauca.

Robles, B. (2011). "La entrevista en profundidad. Una técnica útil dentro del campo antropofísico". Cuicuilco, 18(52), pp. 39-49.

Rodríguez, D. (2013). "El silencio como metáfora. Una aproximación a la Comunidad Sorda y a su sentimiento identitario". Revista de recerca i formació en antropología, 18, pp.1-27.

Skliar, C. (1997). La educación de los sordos. Una reconstrucción histórica, cognitiva y pedagógica, Mendoza: Universidad de Cuyo, EDIUNC.

Stokoe, W. (2005). "Sign language structure: An outline of the visual communication system of the American Deaf". Journal of Deaf Studies and Deaf Education, 10(1), pp.3-37.

Valles, M. (2000). Técnicas cualitativas de investigación social. Reflexión metodológica y práctica profesional. Madrid: Síntesis.

Velasco, H. y Díaz de Rada, A. (1997). La lógica de la investigación etnográfica. Madrid: Trotta.

Woodward, J. (1972). "Implications for sociolinguistics research among the deaf". Sign Language Studies, 1, pp. 1-7.

Wright, G. y Reese, R. (2014). "Strengthening Cultural Sensitivity in Mental Health Counseling for Deaf Clients". Journal of Multicultural Counselling and Development, 43, pp. 275-287. 